\title{
Research Trends
}

\section{Digital Archive Projects at the Center for the Study of Asian Cultures at Kansai University}

\author{
HINO Yoshihiro*
}

\section{Introduction}

From 2011 the Center for the Study of Asian Cultures (CSAC) has been working on the project of digitalizing archives related to East Asian studies held in the Kansai University Library and at CSAC. We have been archiving a broad range of material, from books, art objects, seals, and other physical "things" to travelogues held at the Center and "information" gained from fieldwork done by researchers at Chinese temples and in Hue, Vietnam. We have also been creating databases to store the archived data. These archives and databases are available to the public on the web platform called CSAC Digital Archives. ${ }^{1}$ In addition to the databases of written texts, temples and shrines, monuments, art and historical documents, and ancient texts that we have already made public, we plan to systematically make available databases on topography, films and performances, photographs of China, documents on shipping, and on Vietnam. In addition, we are developing the tools necessary to build databases for the 3-D reconstruction of a Sogdian tomb, individual seals and books of seals from Hakuen Shoin academy, extraction programs for geographic information, and for building indices for full-text data. The CSAC archives will be explained below.

\section{The Databases}

\subsection{Document databases}

At CSAC we have been digitalizing valuable texts stored at the Kansai University Library, mainly personal collections and rare books. We are also moving forward on digitalizing and opening to the public texts owned

\footnotetext{
* Hino Yoshihiro 水野善寛 is a postdoctoral fellow in the Center for the Study of Asia Cultures at Kansai University.

$1 \mathrm{http} / / /$ www.db1.csac.kansai-u.ac.jp/csac/
} 
privately by CSAC scholars and documents held at other institutions whenever they have been requested by CSAC researchers because the content corresponds with the research topics at CSAC. At the heart of the digitalization project is the work done by the photography team organized within CSAC. The data is made public through the document database within the CSAC Digital Archives.

The most representative private collections from the Kansai University Library that are being digitalized are listed below. (Approximate numbers of documents held are in parentheses.)

1). Naitō Bunko (33,500 documents). The documents consist mainly of Naitō Konan's old collection of classical Chinese texts. It also contains the scroll mountings of Shu Shunsui [Zhu Zhiyu] Sensei Shukan (朱舜水先生手簡; Letters of Master Zhu Zhiyu) and Ra Shuku gen [Luo Zhenyu] Sanji rinshinken $j \bar{o} f u k u$ (羅叔言參事臨秦權條幅; Wall Painting of Counsellor Extraordinary Luo Shuyan's Qin Rights). The authenticity is uncertain, but from what is conveyed by Kan fudei (漢封泥; stamps for sealing documents), and letters to Konan clarify the relationship of people who were interacting with him at the time. There are 10,000 of these letters. We have digitalized all of them but because they contain personal information we have not been able to make them public on the internet.

2). Nagasawa Bunko (30,497 documents). These are mainly the Chinese texts from the old Library of Nagasawa Kikuya. This is a collection of vernacular fiction, Chinese dramas, Ryukyuan Mandarin documents, and "Tōwa" (Chinese texts of the mid-Tokugawa period) documents.

3). Nakamura Bunko (33, 491 documents). These are mainly Japanese literary documents from the old Library of Nakamura Yukihiko. It is a collection mainly of printed books and abridgements of the Edo period, and classical Chinese texts as represented by the unique text, Shangshu zhushu (Commentaries on the Book of Documents) from the Southern Song period.

4) Masuda Bunko (16,184 documents). This is the old Library of Masuda Wataru, a scholar of Lu Xun. It contains a book entitled Zhongguo xiaoshuo shilue (A Brief History of Chinese Fiction) given by Lu Xun to Masuda. The collection contains books with comments written by Masuda when he was translating, as well as documents related to the coming to Asia of Western learning.

5). Yoshida Bunko (2,479 documents) This is the old Library of Yoshida Isaburō. It is a smallish collection that focuses mainly on international relations in Asia.

6). Hakuen Bunko (16,954 documents). The books in this collection come originally from Hakuen Shoin, a private Confucian academy in Osaka. It is the Library of the Hakuen Shoin that extends over the three generations and 
four heads of the Hakuen Shoin Academy: the academy's founder, Fujisawa Tōgai, his oldest son, Fujisawa Nangaku; Fujisawa Nangaku's oldest son, Fujisawa Kōku; and Fujisawa Kōha, the second son of Nangaku. The collection contains many manuscripts written by each man as well as many dogeared, treasured tomes.

In addition to the collections mentioned above, we are digitalizing the material in the Iwasaki Bunko, Hirose Bunko, Genbudo Bunko, and other collections. We are also digitalizing material related to Japanese history purchased by Kansai University Library through a 1964 private university grant. These documents are not being systemically digitalized by collection; rather, the researchers and scholars at CSAC select the documents they think necessary for research on East Asia to be digitalized. These materials are not only available through the CSAC Digital Archives, but are also directly accessible through the KOALA ${ }^{2}$ Library search system used by the Kansai University Library.

Personally-held collections that we have been digitalizing include Chinese language and Chinese language-education related texts from the old Library of Ozaki Minoru (Professor Emeritus in the humanities department of Kansai University), CSAC Professor Uchida Keiichi's personal collection, and over 10,000 books donated by Nihon University Professor Emeritus Masuzawa Akio, a scholar of Chinese educational history. All of the hard copies of these texts are on the bookshelves of CSAC. When the materials on Chinese language education in the umbrella organization of CSAC, the Institute of Oriental and Occidental Studies, are included, the collection comprises one of the world's largest collections of Chinese language education from the latter nineteenth to early twentieth centuries, all of which are in the process of being digitalized. In addition, we are digitalizing the collections of CSAC members, such as that of Professor Inui Yoshihiko on Edo period Chinese classical texts for children, Professor Okumura Kayoko's documents on Chinese language interpreters in the Edo period, Center Director Matsuura Akira's documents on shipping, and Professors Shen Guowei's and Uchida Keiichi's English-Chinese dictionaries. We also plan to make public other holdings through cooperation with university libraries outside Kansai University, including Aichi University Library's The Awakening of China, Problems of the Far East, Foreign Practice, and the Guanhua zhinan (官話指 南) held in Kobe City University of Foreign Studies. Further, we have made arrangements to digitalize rare old books, such as the original copy of Romance of the Three Kingdoms, held in the Escorial Palace in Spain and rediscovered by CSAC Professor Inoue Taizan, as well as other extant clas-

2 http://opac.lib.kansai-u.ac.jp/ 
sical Chinese texts and other documents held in institutions on the Iberian Peninsula (Spain and Portugal).

The number and content of the documents photographed so far are listed below. Of these, about half are already open to the public and can be read.

Kansai University Library

\begin{tabular}{|r|l|l|l|l|l|l|l|r|r|}
\hline $\begin{array}{r}\text { 吉田 } \\
\text { Yoshida }\end{array}$ & $\begin{array}{l}\text { 中村 } \\
\text { Nakamura }\end{array}$ & $\begin{array}{l}\text { 広瀬 } \\
\text { Hirose }\end{array}$ & $\begin{array}{l}\text { 立武洞 } \\
\text { Genbudōo }\end{array}$ & $\begin{array}{l}\text { 内藤 } \\
\text { Naitō }\end{array}$ & $\begin{array}{l}\text { 長澤 } \\
\text { Nagasawa }\end{array}$ & $\begin{array}{l}\text { 増田 } \\
\text { Masada }\end{array}$ & $\begin{array}{l}\text { 岩崎 } \\
\text { Isawaki }\end{array}$ & $\begin{array}{l}\text { 泊園 } \\
\text { Hakuen }\end{array}$ & $\begin{array}{l}\text { Rare } \\
\text { Books }\end{array}$ \\
\hline 4 & 24 & 10 & 33 & 272 & 388 & 391 & 379 & 1897 & 527 \\
\hline
\end{tabular}

Personal Collections, etc.

\begin{tabular}{|l|r|l|l|l|l|l|}
\hline $\begin{array}{l}\text { 乾 } \\
\text { Inui }\end{array}$ & $\begin{array}{l}\text { 鳟澤 } \\
\text { Masazawa }\end{array}$ & $\begin{array}{l}\text { 松浦 } \\
\text { Matsuura }\end{array}$ & $\begin{array}{l}\text { 内田・尾崎 } \\
\text { Uchida/Ōzaki }\end{array}$ & $\begin{array}{l}\text { 奥村 } \\
\text { Okumura }\end{array}$ & $\begin{array}{l}\text { 沈 } \\
\text { Shen }\end{array}$ & $\begin{array}{l}\text { Institute of Oriental } \\
\text { and Occidental } \\
\text { Studies }\end{array}$ \\
\hline 81 & 164 & 48 & 832 & 8 & 10 & 87 \\
\hline
\end{tabular}

Other Institutions

\begin{tabular}{|c|c|c|}
\hline Aichi University & $\begin{array}{l}\text { Kobe City University } \\
\text { of Foreign Studies }\end{array}$ & Spain \\
\hline 3 & 2 & 18 \\
\hline
\end{tabular}

The reason the digitalized documents of the Hakuen Bunko dominate the list is that we have been jointly working on the project with CSAC member Professor Azuma Jüji from an early stage, digitalizing the Fujisawas' own writings. We created a specialized website for the Hakuen Bunko collection entitled WEB Hakuen Bunko in addition to the one accessible from the CSAC Digital Archives. Besides the search system we had already built, in June 2014 we succeeded in creating and making public an always up-to-date index of bibliographies registered in the database that is available to the

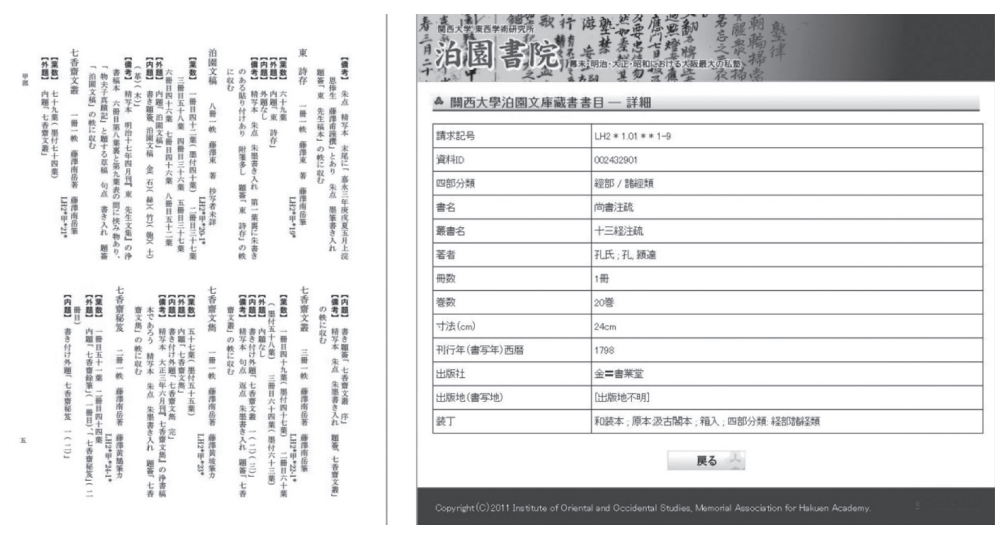

Fig. 1 PDF Index (Left) and Details on Database Screen (Right)

By clicking on the book title in the PDF index on the left, it is possible to link to the detailed screen on the right. 
public as a PDF file. By linking from the PDF item to the database, the user can do a general search even if he does not know the original keyword.

Thus, CSAC's project to digitalize works and open them to the public has made it possible to see documents in the Kansai University Library, the CSAC Digital Archives, and WEB Hakuen Bunko on a browser. We are using a customized version of BookReader, an open-source viewer provided by Internet Archives. In contrast to the majority of horizontally-written texts in the Internet Archives' BookReader, where books open from the left, CSAC is digitalizing on the precept of right-opening books. Also, because it is necessary to do full-text searches with multi-bite characters, we have created a uniquely customized version to handle this difference. The reason we chose this viewer was that because most viewers use FLASH at many organizations in Japan today, the problem arises that users cannot read such texts on tablets, smart phones, and other terminals that are being used to access sites in increasing numbers. To handle this problem we used a viewer built mainly on JavaScript and html.

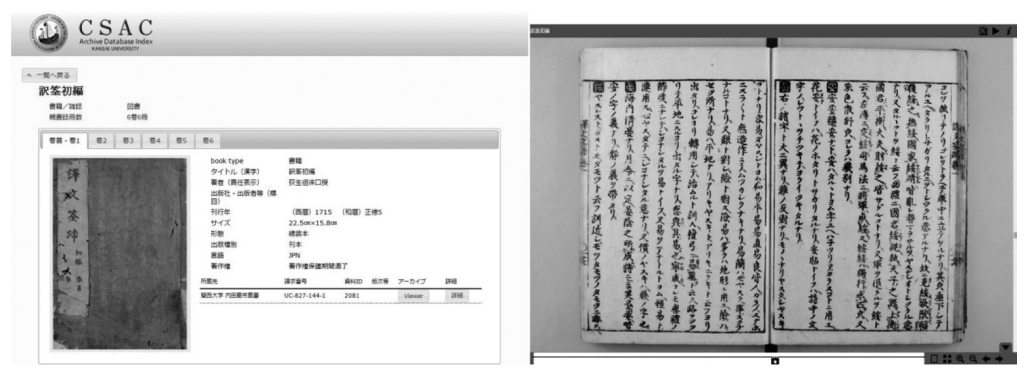

Fig. 2 CSAC Digital Archives Document Database Screen (Left) and BookReader (Right)

For full-text documents, not only can full-text searches be done simultaneously in multiple documents within the databases, but now it is also possible to do full-text searches on each individual document within the viewer. This full-text search is built on Groonga, a full-text search engine with open-source custom store functionality, and MySQL, which is based on the Library Mroonga that allows high-speed searches of full texts. It is also possible to search variant Sinograph forms, such as traditional and simplified Chinese characters, pre-war and post-war Japanese characters, and dictionaries with Sinographic variant forms. 


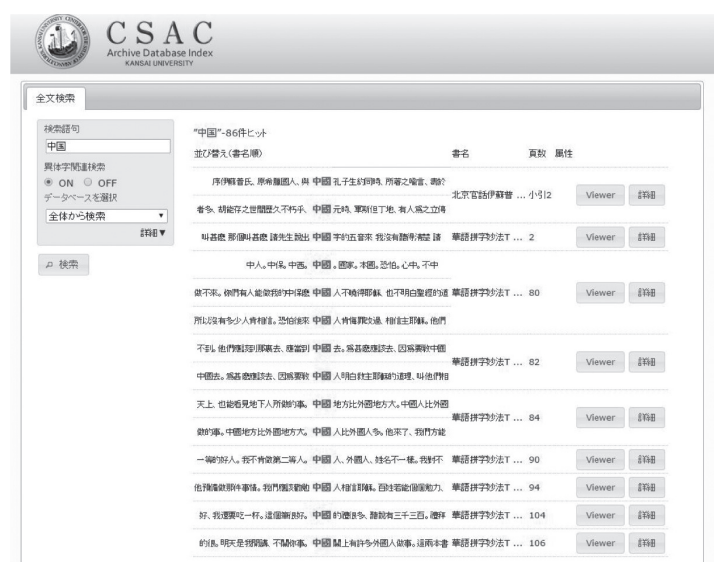

Fig. 3 Full-text Searches

In addition to written texts, we have also made publically available on WEB Hakuen Bunko the "Hakuen seal collection," which is a digitalized database of stamps and seals originally from the Hakuen Bunko. In this Hakuen seal collection, seals can be searched from the seal face, from a side subsection, or from the explanation. In the detailed screen, seal faces and books of seals can be displayed.

\section{泊圈雨}
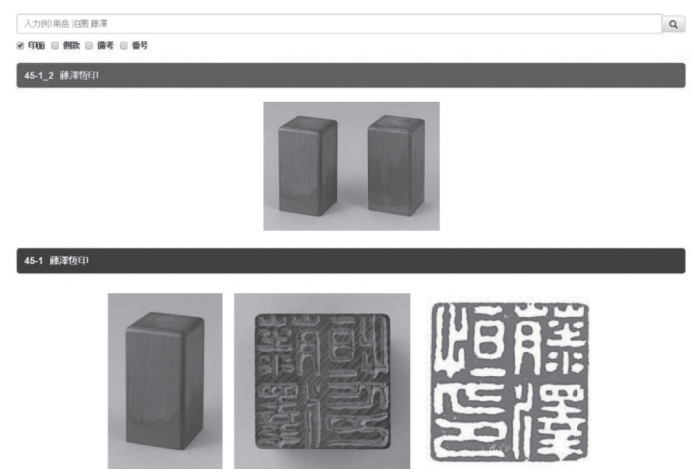

Fig. 4 Hakuen Seal Collection

\subsection{Art and Historical Documents Databases}

In addition to the written document databases opened to the public, we are also preparing to make accessible databases on art and historical documents, including several hundreds of items held in the personal collections and rare book archives in the Kansai University Library. There is a broad range of material, from historical documents to art objects; at the heart of this 
database are the more than 350 paintings from the Edo-period Osaka painting circles. We are planning to make available to the public the many woodblock prints of elephants, beginning with Ogata Tankō's nineteenth-century Zō no emaki, a depiction of an elephant brought to Japan from abroad in the Edo period. ${ }^{3}$

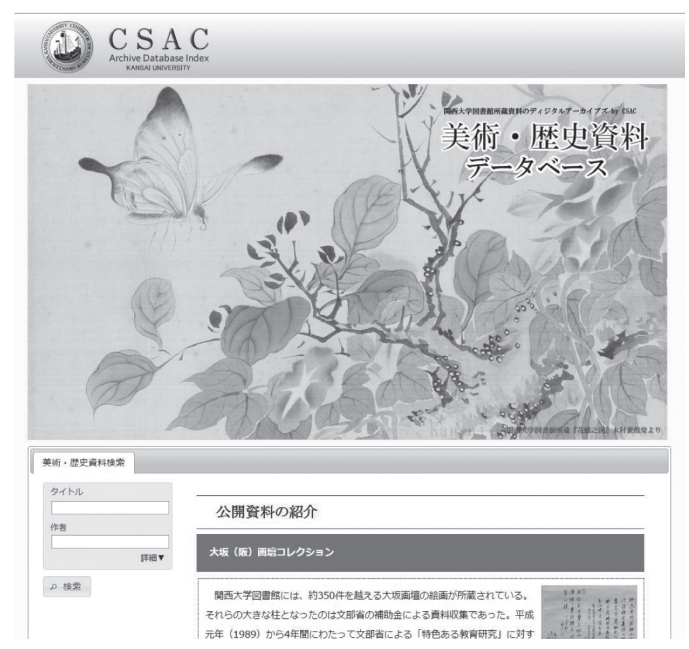

Fig. 5 Art and Historical Document Database

We are going to display digitalized data with the image-specific viewer ImageViewer in addition to BookReader, with which we have made the document database open to the public.

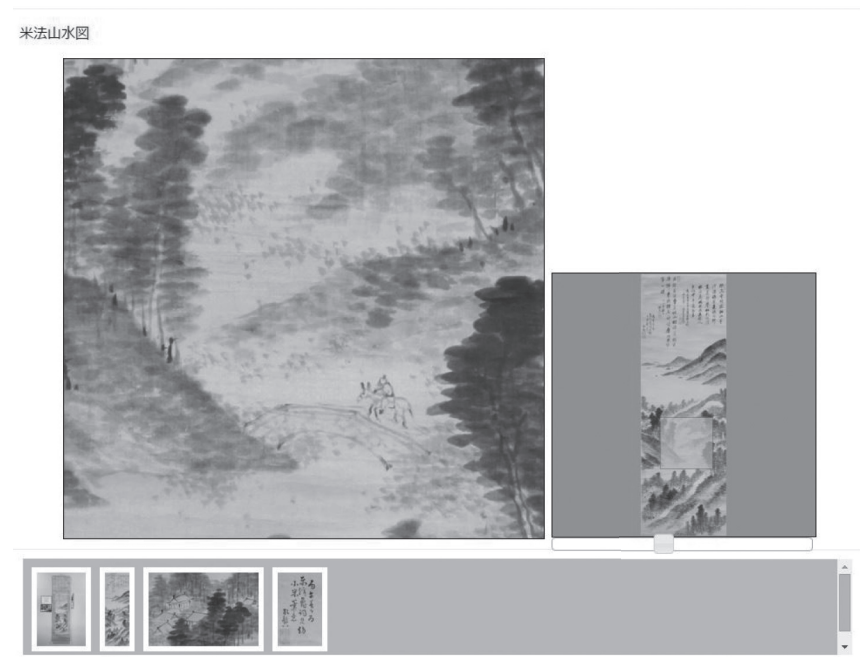

Fig. 6 Art and Historical Document Database ImageViewer

3 From the explanation in http://www.db1.csac.kansai-u.ac.jp/csac/art.php 
Like BookReader, this viewer also does not use FLASH, but is built using only JavaScript and html. Unlike BookReader, however, it can be used to smoothly expand or shrink each page of images as appropriate.

\subsection{Ancient Document Database}

In terms of the ancient document database, we are preparing the public disclosure of mainly ancient books kept in the Kansai University. LibraryCurrently we are experimenting with just three items: a black-seal document that belonged to Oda Nobunaga; a letter written by Toyotomi Hideyoshi; and a draft note written by the shugo (governor) of Yamashiro Province, Yūki Mitsubushi, but we plan to open more documents to the public in the future. In terms of function, it is possible to view the documents by using searches for reprints, full-text searches, PDF displays, and BookReader.

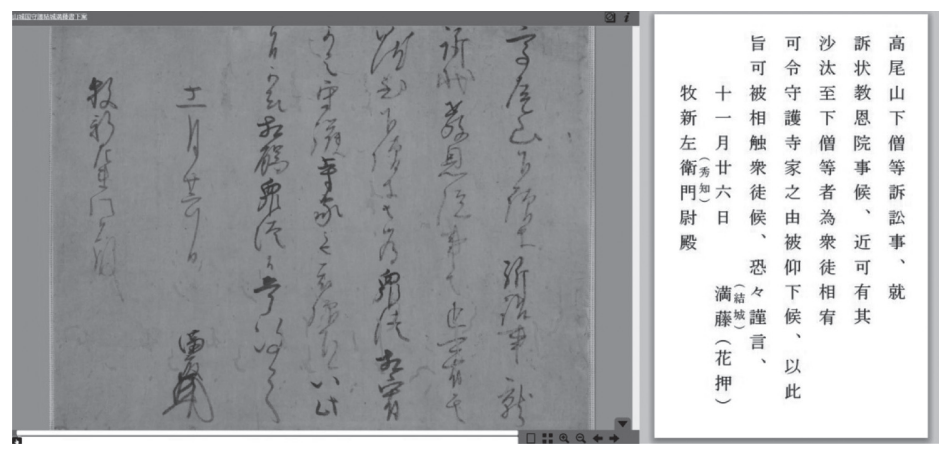

Fig. 7 Ancient Document Database

\subsection{Monument Database}

This database was built by CSAC member Professor Moribe Yutaka and his research group. They are now mainly collecting and disclosing Sogdian epitaph inscriptions. Not only are the screen images of the originals displayed, but so is the monument text data that is carved into the epitaphs.
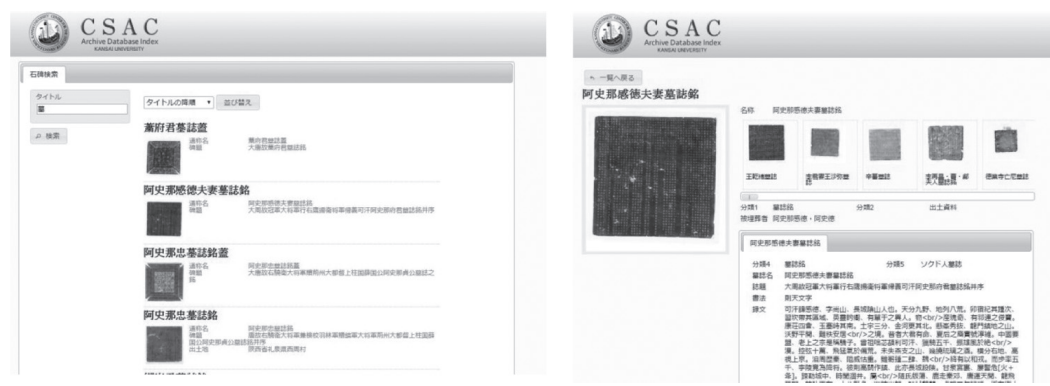

Fig. 8 Monument Database 


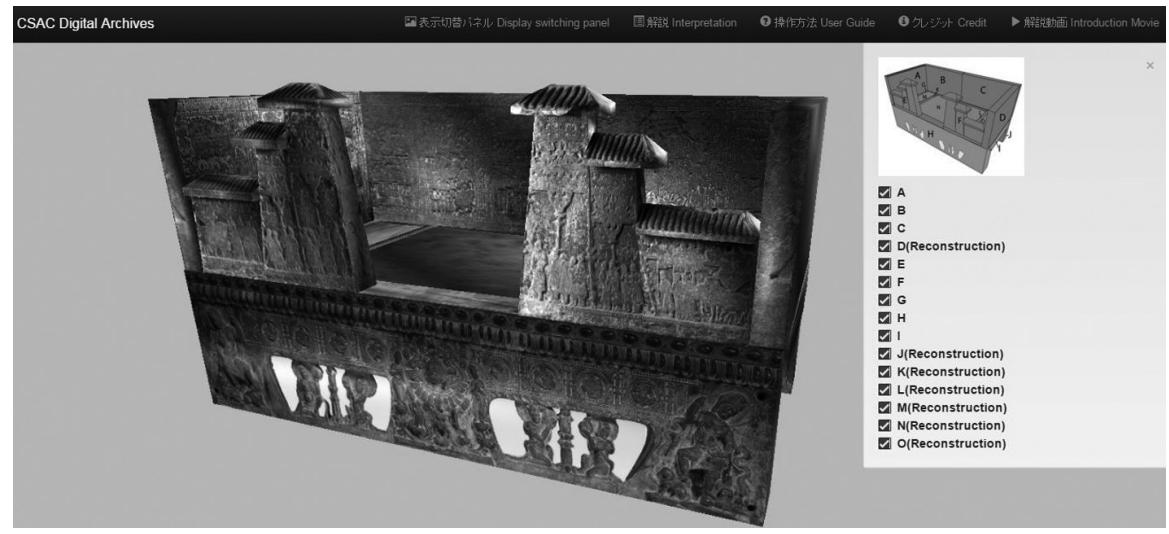

Fig. 9 3-D Model of Sogdian Funerary Objects Being Developed

In addition to creation of the monument database, we have also built a 3-D model of Sogdian funerary objects. This project involved replication in virtual space of eight separate stone slabs thought to have been excavated in Anyang at the beginning of the twentieth century. Today these stone slabs are held in the Museum of East Asian Art in Cologne, the Guimet Museum in Paris, the Museum of Fine Arts, Boston, and the Freer Gallery of Art in Washington D.C., respectively. Because it is very difficult to reassemble the actual pieces of stone we built a 3-D model from photos and animation to replicate what it looked like at the time.

\subsection{Chinese Photo Database}

The database of Chinese photos was built with the aim of uploading rare photos of China held at CSAC. The data available to the public is organized according to who originally owned the photos. The most important collection is the thousands of photos taken by Kansai University Professor Emeritus Fujiyoshi Masumi during fieldwork. The photos are of China between the 1980s and 1990s. The database also contains 1500 photos taken in China between the 1970s and 1980s and donated to CSAC by Meiji Gakuin
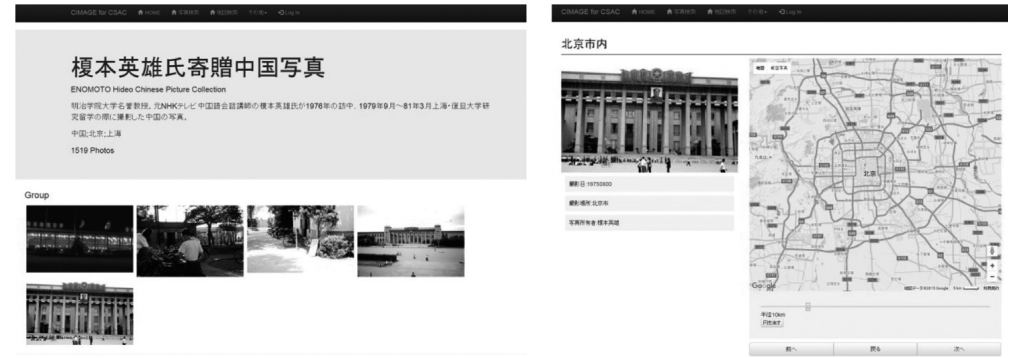

Fig. 10 Database of Photos of China 
University Professor Emeritus Enomoto Hideo. In particular, the photos taken in August, 1975 during the Cultural Revolution, are extremely valuable. Besides these, in the collection of texts donated by the aforementioned Masuzawa Akio there are photos taken in China during the 1920s organized into personal albums. Among the photos are pictures of the Great Wall, the Summer Palace of Beijing, and other tourist sites. The collection also contains photos of a person named Sugimoto, from the Mitsui Shoin Academy, including Wu Taishou, the cousin of Wu Qitai, who penned the Guanhua zhinan and was the headmaster of the Mitsui Shoin. There are no other known photos of Wu Taishou aside from those in this album. In addition, there are many albums related to schools in pre-war Taiwan and China that are of great use for researching people who were important at the time. We are thinking of creating a database for these photos.

We are building this database by using a system that makes it possible to search not only by photos and keywords, but by GPS information, such as locale.

\subsection{Database of Temples and Shrines}

The database of temples and shrines centers on the research group under CSAC Professor Nikaido Yoshiro, and makes accessible to the public data on local Daoist and Buddhist temples found mainly on the Chinese mainland and in Taiwan. Even without a keyword, by mapping the location of the temple or shrine it is possible to search directly from the map. Information on each temple and shrine includes the name, location, year built, deity enshrined, people related, research on the temple, and other information. It is possible to search such information using singular or multiple search arguments.
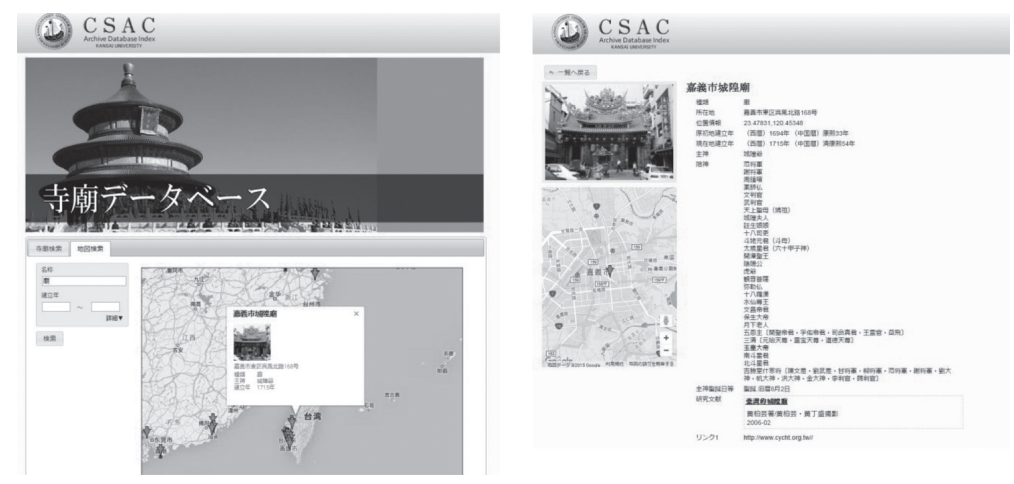

Fig. 11 Database of Temples and Shrines

\subsection{Other Databases under Construction}

Besides the above databases that are in the process of being made public, 
we are also progressing on the project of digitalization and creating a database for Center Director Matsuura Akira's materials on shipping. We are preparing to make various types of data available in a unified system, including shipping routes in East Asia, guidebooks, photos of ships, and journals.

Our next project is the building of the database for Sugawara Yoshino's research group on films and performance. This is a database of film and performance information carried in the newspaper Shen Bao (申報) published in Shanghai from the late nineteenth to early twentieth centuries. As in the case of the database for temples and shrines, GPS information for all performances will be uploaded, making it possible to search not just from articles but from maps as well.

Besides digitalization of material centering on the documents I've discussed above, we are also working on architecture for a database that uses GPS information gained from topographical data from fieldwork and travelogues. It is an attempt to create a database based on analysis of information from Aurel Stein's second Central Asia expedition, the results of which are in Stein's report, Serindia; GPS data; and travelogues written by the Ming period travel writer $\mathrm{Xu}$ Xiake.
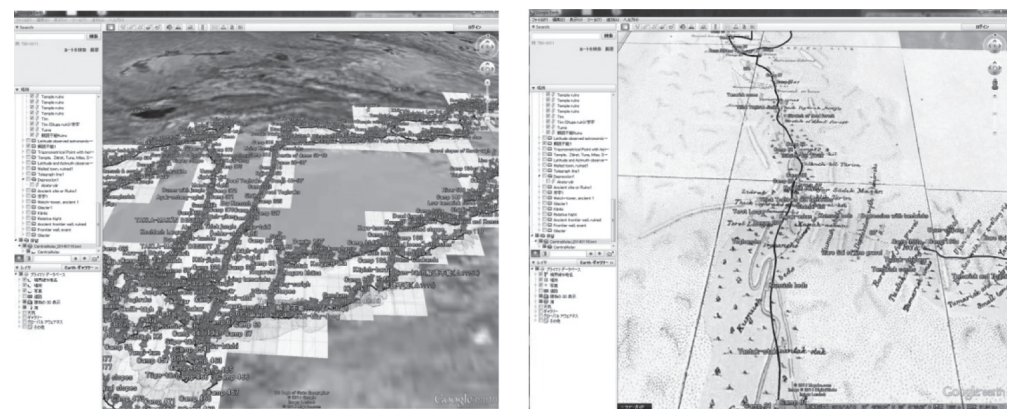

Fig. 12 Mapping Work (Overall) Using Google Earth

Lastly, we also plan to create in stages a Vietnam database for documents such as cadastral books and genealogies from Hue, and fieldwork records from Hue conducted by the Institute for Cultural Interaction Studies (ICIS) at Kansai University, such as fieldwork records, photographs, and bookls. 